\title{
Psychiatric-mental health nurse practitioner student preceptorship: Perspectives on the clinical training
}

\author{
Horace Ellis* \\ Jackson Memorial Hospital, Miami, Florida, United States
}

Received: May 21, 2018

DOI: $10.5430 /$ jnep.v8n12p82
Accepted: July 22, 2018

URL: https://doi.org/10.5430/jnep.v8n12p82

\begin{abstract}
As today's health-service delivery continues to evolve and transform, keeping pace with the training needs of professionals entrusted to deliver quality, competent care is itself an evolutionary and multifaceted academic undertaking. In the United States, psychiatric mental health nurse practitioners (PMHNPs) have been evidenced as formative, effective, and necessary contributors to quality, cost- effective patient, family, and community-based mental health care across the lifespan. The education and certification processes for PMHNPs involve a comprehensive and rigorous combination of theoretical course-work and clinical practicum guided by the concepts and principles of the preceptorship model. The purpose of this paper is to use the available literature to discuss and gain insights into some clinical and educational perspectives influencing PMHNP students' practice preparations within the context of the preceptorship-paradigmatic relationship. Along with adding to the literature, this paper could have important implications from the standpoint of the PMHNP student-faculty-preceptor model.
\end{abstract}

Key Words: Preceptoring, Advanced practice, Psychiatric mental nursing

\section{INTRODUCTION}

As the United States seeks to reform its mental health service delivery system, it has critically influenced university colleges of nursing to revise their educational curricula to meet the requirements of advance practice nursing (APNs) roles, including those of psychiatric mental health nurse practitioners (PMHNPs). ${ }^{[1-3]}$ PMHNP is a unique titled specialty certification within the discipline of nursing where nurses are prepared to provide direct psychiatric/psychosocial care to individuals/families across the lifespan. Clinical practice preparation for PMHNPs is achieved through advanced level comprehensive university-based training program models that include clinical preceptorship. ${ }^{[4]}$ PMHNP preceptorship involves the integration of theoretical knowledge with practice skills, and where preparation for future clinical practice is emphasized and facilitated. However, despite a significant body of multinational literature on the concept of preceptorship, current scholarly work on the topic of PMHNP preceptorship as a specialty is indeed sparse $;^{[3,5]}$ thus compelling this author to cite some seminal sources for their scholarly relevance. It stands to reason therefore, that contemporary scholarly reflection on the clinical preparation of PMHNP is applicable in understanding some of the characteristics of student-preceptor-faculty paradigmatic relationships within such a unique practice specialty. The purpose of this paper is to use the available literature to discuss and gain insights into some clinical perspectives influencing PMHNP students' practice preparations within the context of the preceptorshipparadigmatic relationship.

*Correspondence: Horace Ellis; Email: hellis@jhsmiami.org; Address: Jackson Memorial Hospital, Miami, Florida, United States. 


\section{A CONCEPTUAL REFLECTION}

In reviewing the nursing literature, it is evident that preceptorship can be conceptualized as a mid-range theoretical construct that forms the framework for the practice specialty. ${ }^{[5-9]}$ As a concept, Marfell ${ }^{[10]}$ (2011) defined nursing preceptorship as the relationship between two nurse learners, one novice and one experienced in their chosen professional specialty. In the PMHNP-student relationship, the nurse practitioner is the preceptor with the knowledge and expertise to effectively: (1) orient the student to the practice specialty, (2) bridge theory to practice, (3) teach required skills and techniques, (4) evaluate clinical progress and outcomes, and (5) support professional transitioning. ${ }^{[6,11]}$

The PMHNP student preceptorship requires dualistic relationship-commitments for the acquisition of specialized skillsets by the triadic university-faculty-student agreement, in a practicum environment. This practicum is under the observation, mentoring, and evaluation of the preceptor whose personal attributes and clinical expertise are well established and highly sought after by university colleges of nursing. ${ }^{[1,4,12]}$ This structured learning process is necessary since the specialized nature of PMHNP clinical environment can expose students to unique challenges much different from other aspects of nursing training. For example, meeting patients' psychiatric/psychological, physical/emotional, and socio-cultural needs are grounded in complex and multidimensional conceptual and theoretical dynamics and models that require wide-ranging specialized skills and techniques. Despite being at an advanced educational level, students are susceptible and often confronted with a variety of challenges at a human level. ${ }^{[13]}$ These challenges may be based on their naive implicit or explicit conscious or unconscious egoic emotions clashing with the patient's psychopathology. Additionally, students' perceptive and ideological worldviews could skew the phenomenological reality of the clinical situation or environment. An example would be misperceiving an anxious patient as agitated, an assertive patient as angry, or psychotic behavior as violent or aggressive, dangerous, or threatening. ${ }^{[14]}$ For these reasons, a crucial role of the PMHNP preceptor involves drawing on their knowledge of theoretical and conceptual principles and frameworks to inspire and support students, identify and correct their unconscious biases, and ultimately develop the professional attributes for practice. ${ }^{[13,15]}$ These practice constructions are grounded in the concept of professional intelligence - the acquisition of self-awareness, self-reflection, self-regulation, and self-motivation. ${ }^{[15]}$ Likewise, Buck \& Lysaker (2010) and Fitzpatrick \& Gripshover $(2016)^{[11,13]}$ alluded that critical investigative thinking is necessary for the development of the knowledge-skill-competency set required for safe and effective practice.

\section{THE PRECEPTOR-STUDENT RELATION- SHIP}

The clinical practicum preceptorship-relationship model is integral to the theoretical and practical development of nursing students across educational levels and practice specialties. ${ }^{[8]}$ Intrinsic to the PMHNP-student preceptorship andragogic model are the theoretical and philosophical assumptions that it builds on students' maturity and experiences to provide the most effective opportunity for the acquisition and development of advanced knowledge and specialized clinical skills. ${ }^{[8]}$ This complex teaching process is accomplished in part by preceptors not only being experts in clinical content but also having positive personal attributes in a nonhierarchical environment favorable for learning. ${ }^{[5,12]}$

Descriptive studies on preceptors' pedagogical strategies and techniques ${ }^{[9,16]}$ fit well within the context of understanding the PMHNP student-preceptor relationship model where effective learning is a targeted measurable objective. Both studies illustrated that in order for the professional contract to cohere, the clinical environment must be able to provide the trust and security conducive to the student's academic growth. Within these constructs, preceptors play key roles in providing the educational supervision and supportive evaluation to students as they prepare to transition into new clinical and practice roles. ${ }^{[8]}$

Haitana \& Bland (2011) and Luhanga et al. $(2010)^{[8,12]}$ emphasized that preceptors, regardless of clinical level or specialty, are expected to be knowledgeable, nurturing, and committed to their professional roles. Additionally, Elisabeth et al. (2009) $)^{[16]}$ and Trede et al. (2016) ${ }^{[9]}$ highlighted the importance of preceptors' pedagogical and epistemological competence in order to facilitate best practice clinical scholarship. Lucas \& Bischof (2014), ${ }^{[7]}$ Schumacher \& Risco (2017), ${ }^{[17]}$ and Weber et al. (2016) ${ }^{[18]}$ noted that preceptors who lack pedagogical abilities on accessing and utilizing evidence-based knowledge may have difficulty engaging and/or inspiring students during the preceptorship relationship-building process. Intrinsically, PMHNP preceptors' characteristics include: The commitment to give back as well as the enthusiasm to take on the demanding and timeconsuming challenges and responsibilities in order to share their expertise with students. ${ }^{[1,12]}$ These characteristics are rooted in the principles of mindful unconditional regard and conscious intentionality which are core caring essences. Additionally, PMHNPs have referential powers that sometimes extend beyond the time frame of their students' contracted relationship. This usually occurs as newly graduated $\mathrm{PMH}-$ 
NPs acclimate to their new practice and role socialization. In part, this influential power-relationship often manifests in forms of expert mentoring, clinical consultation/supervision (formally or informally), or professional referencing.

PMHNP preceptors are considered experts with referential integrity in their practice areas. They are in high demand and short supply; and are in an ideal position to assist in preparing students for the high quality and rewarding PMHNP workforce. Other key roles of the PMHNP preceptor include providing the necessary safe space for teaching and learning within a clinical environment that can be challenging, intimidating, or even unpredictable to the novice/naive student. The PMHNP preceptor also carefully evaluates how the relationship is configured, maintained, and educationally evolved. ${ }^{[1,8]}$ Within these dualistic constructs, two salient concepts are identified: (1) the "preceptor consistency"[8] and (2) the student's "emotional intelligence". ${ }^{[15]}$ Whereas the preceptor consistency helps the preceptor become familiar with the students and helping them to feel clinically secure and supported $;^{[1,8]}$ the emotional intelligence is the student's ability to effectively manage their own emotions and behaviors, navigate social complexities, and make sound clinical decisions. ${ }^{[15]}$ These are critical constructs that help students develop behavioral and emotional regulations while effectively navigating a clinical environment that is at times perceived as socially complex.

Imbedded within the preceptor consistency and the students' emotional intelligence construct are concepts such as selfawareness, self-reflection, self-regulation, transparency, genuineness, the motivation for scholarly inquiries combined with a passion for teaching. Additionally, the preceptor helps students reconcile and re-frame differences between their own world views and clinical realities. This is accomplished by using critical thinking and reasoning to analyze clinical data and/or explain case presentations/scenarios, or to manage the milieu dynamics. It is also important to mention that the preceptorship relationship model provides a two-way teaching and learning opportunity for both preceptees and the preceptors. Just as the students rely on the preceptors' knowledge and teaching expertise to actualize their desired knowledge and skills; preceptors are aware that students also transmit important clinical and practice information within the relational environment.

\section{THE CLINICAL-PRACTICE SOCIALIZA- TION}

Creative new approaches must be developed and implemented to socialize and transition robustly trained PMHNP graduates into the practice specialty. ${ }^{[1,11,19]}$ Embedded in these approaches is the concept of the preceptorship clinicalpractice (role) socialization aimed at building sustainable interprofessional collaborative relationships. This is a relationship based on mutual professional partnership aimed at achieving best teaching-learning and eventual practice outcomes. ${ }^{[1,5,6]}$ The literature provides conceptual perspectives on the benefits of clinical-practice socialization to students. Some examples include: (1) clarifying role socialization within contexts of professional development, (2) easing social discomfort and clinical practice uncertainties, (3) building collaborative stakeholder connectedness and relationships, (4) increasing emotional intelligence, and (5) building research, practice and leadership capacities. ${ }^{[1,5,13,15,17]}$

Phenomenologically, the process of PMHNP students' role socialization can present interpersonal and professional challenges within the clinical environment. For instance, clinical situations or presentations that may be characteristically and contextually understandable to the experienced PMHNP preceptor could be personally or even professionally uncomfortable or challenging to the novice/naive student. In such cases the clinical-practice socialization provides a professionallystructured and partnered relational engagement type of resolution pathway benefiting both student and preceptor. ${ }^{[1]}$ Under the guidance of the preceptor, each clinical experience is a partnership engagement aimed at helping PMHNP students to develop the self-concept and emotional intelligence needed for future clinical practice. ${ }^{[1]}$ For example, being mindful that patients' thought, mood, and behavior often suggest underline meanings that can be explained biologically or sociologically; and therefore responses to those behaviors must be intentional and purposeful for the individualized therapeutic benefit of those patients. Additionally, the PMHNP preceptor incorporates principles of andragogy, uses case examples and role playing as experiential teaching and learning tools while providing students with constructively corrective feedback. ${ }^{[5,17]}$ Intrinsically, the literature supports PMHNP student clinical-practice socialization within the context of the preceptor relationship. This is a paradigm designed to stimulate professional development while facilitating role transitional methods from novice to expert practitioners. $^{[11,19]}$

\section{THE KNOWLEDGE-SKILLSET DEVELOP- MENT}

The preparation of nurses at any level to work with individuals with mental illness requires the acquisition and incorporation of diverse knowledge skill sets. This includes having favorable perceptions and attitudes toward mental illness and those affected. ${ }^{[13,22]}$ In part, the development of knowledge and practical skill sets is accomplished through the acquisi- 
tion of cognitive, intellectual and interpersonal abilities. ${ }^{[15,20]}$ Developing practical skillset begins with the ability to use principles of empathy, active listening and nonjudgmental attitude to establishing therapeutic alliance with patients, while developing self-awareness to effectively manage transference and countertransference experiences. ${ }^{[13]}$

Other practical skillset include structurally and sequentially conducting the psychiatric interview, contextually analyzing and interpreting the history; formulating the working and differential Diagnostic and Statistical Manuel (DSM), Fifth Edition diagnoses; construct a solid case formulation and prescribe the appropriate pharmacological or nonpharmacological treatment. Additionally, students should be able to use the available technological tools to document a thorough and linguistically correct clinical note. To that end, students should be epistemologically driven, and have the ability to independently apply scientific and theoretically-based critical and analytical thinking to enhance their clinical experiences. ${ }^{[11]}$ Essentially, students are taught to apply the invisible processes of critical thinking to understand and explain the visible characteristics to varied clinical presentations. In other words, to be able to critically analyze and decipher that the personal attacks of an angry/irritable patient diagnosed with bipolar disorder is part of the symptom domain of that condition and that medication issues or other psychosocial need might need addressing. Staying calm while acknowledging and supporting patient's feelings, yet being directively explorative without challenging of defensive behaviors are helpful communication strategies that students can learn to apply as part of the invisible process of critical thinking skillset. Students are also taught to apply these concepts to better manage their own anxieties, perceptions, and ideological attitudes. This includes but not limited to working through countertransference-triggered attitudes, emotions and behaviors toward patients. To use an example; avoiding some stereotypical clichés such as: "he is an Axis II" or "she is a borderline". Balancing the complexities of the psychiatric setting with the learning needs of the PMHNP student can be a challenging task for the preceptor. For example, the fast-pace and time-consuming nature of the psychiatric clinical environment can impact both patients' care delivery and the learning needs of the student as well as the preceptor's ability to balance being a patient care provider and an academic lecturer. ${ }^{[8]}$ For these reasons, advanced-level nursing students are expected to enter the clinical setting with academic baseline knowledge and experience within their specialty.

At the PMHNP level, students are expected to independently perform most of the basic skillsets required for the specialty. Such as: demonstrating basic therapeutic communication Published by Sciedu Press skills/techniques, being familiar with and apply theoretical perspectives and frameworks, as well as articulating some knowledge of major medication categories. Thus, they are expected to draw on their reflective thinking as well as theoretical and experiential knowledge when clinically engaged. These key principles help students transfer theory into practice, clarify assumptions, and understand clinical realities. Work by Benham \& Hawley (2015) ${ }^{[21]}$ illustrated that deficiency in critical thinking and decision-making skills by APN students narrows their ability to critically evaluate patient care. Arguably, experience level of students was identified as a factor influencing preceptors' willingness to precept. ${ }^{[1]}$ The preceptor works with each student based on his/her personal/clinical experience, learning style while having realistic expectations of that student. The preceptor also balances the fast-pace clinical environment with the students' learning needs by constantly being aware of, and monitors the types as well as the numbers of patients a student is able to comfortably manage without compromising care. In essence, in busy clinical environments, patient care always takes priority over teaching. ${ }^{[6]}$

Addressing potential baseline knowledge and skillset gaps among PMHNP students will require university colleges of nursing to make curricula adjustments reflecting entrylevel clinical competencies. This can be achieved through pre-program comprehensive-type clinical skills verification, carefully designed psychiatric clinical observership, or postgraduate residency programs in collaboration with major teaching facilities. ${ }^{[4]}$ These are immersive experiences that can adequately serve as baseline clinical practice preparation for PMHNP students or new graduates. Students may also benefit from starting their clinical preceptorship after completing the first semester of core coursework that include a comprehensive review of psychiatric mental health nursing. This will in part provide them with new or refreshed knowledge on some major constructs such as: (1) principles of therapeutic communication skills/techniques; (2) major theories and concepts influencing psychiatric nursing practice; (3) the structure and process of the psychiatric evaluation, diagnosing and treatment planning: and (4) the various categories of disease process and psychopharmacology.

A study by Kirkbakk-Fjaer et al. (2015) ${ }^{[22]}$ identified that nursing preceptors are concerned about students' inability to exercise basic theoretical and practical mental health knowledge and skills, and articulated opportunities for educational organizations to rectify these deficiencies. Although the study evaluated undergraduate students, it can be applied to broader academic areas (i.e., PMHNP programs) within the context of further scholarly applications or examinations. Notwithstanding, Munnukka et al. (2002) ${ }^{[23]}$ seminally rea- 
soned that teaching mental health nursing in the classroom is generally too artificial or orthodoxy and not representative of real-world situations. The authors added that despite the availability of technologically simulated classrooms, ${ }^{[24,25]}$ or live models to practice, it is difficult for students to imagine and transfer those controlled scenarios into real life situations. ${ }^{[23]}$ Based on this author's clinical observation, as well as observed by Elisabeth (2009) ${ }^{[16]}$ and Benham \& Hawley's (2014), ${ }^{[21]}$ these deficits impede teaching the advanced level skills needed to practice in the constraint of a fast-paced multifaceted and challenging clinical environment. Given these challenges, some enthusiastic PMHNP preceptors utilized what this author dubbed the upside-down triangle approach to teaching - a phenomenological-adjusted approach to teaching general PMH nursing theories and clinical skillset to advanced level students. For example: some basic elements of therapeutic interaction/communication, assessment skills/techniques; psychopharmacology, as well as some important psychoterminologies. The triangle-based teaching and learning approach is based on the premise that knowledge and skillset development begins at the broad-based and general levels and progresses to the narrow and specific as practice becomes more advanced and specialized. It is noteworthy that Elisabeth et al. (2009) ${ }^{[16]}$ viewed similar approaches as rare preceptor pedagogical competence.

\section{THE EDUCATIONAL-CLINICAL-PRACTICE PARADIGMS}

Achievements in the educational, clinical, and practice preparation of PMHNPs is grounded in a comprehensively integrated theoretical and clinical paradigm that includes primary, secondary, and tertiary interventions across developmental levels. ${ }^{[4]}$ This clinical paradigm spans the spectrum from acute to chronic and from mild to severe psychiatric/psychological/psychosocial conditions that are multifaceted and complex. Becoming a PMHNP is predicated on well-designed faculty-student-preceptor curriculum-guided pedagogical and epistemological andragogic models aimed at achieving sustainable practice opportunities. ${ }^{[3,18]}$ These models facilitate the development of knowledge and skill competencies and those essential roles for interactively comprehensive care and service delivery with an emphasis on measured quality outcomes. Tusaie $(2013)^{[4]}$ noted that the education and training of PMHNPs has transitioned from earlier pedagogical models to new types of practitioners with expanded and blended roles and competencies that meet contemporary educational, administrative, clinical, and practice paradigms. These models require that academic institutions design the types of PMHNP training programs that cultivate and nurture (1) the preceptor-student relationship,
(2) clinical-practice socialization, and (3) knowledge-skill development processes.

The educational, clinical, and practice preparation, and the ultimate certification of PMHNPs is in part supported by the Institute of Medicine (IOM) (2011) declaration that nurse practitioners must be allowed to practice to the full extent of their education and training. Such declaration helps to strengthen advanced practice PMH nurses' motivation to eradicate barriers to care using tri-directional models such as integration, collaboration, and expansion of care services for mentally-ill individuals and their communities. ${ }^{[26]}$ The expertise of PMHNP preceptors put them in unique positions to impart valuable educational, clinical, research, and leadership experiences that reflect the philosophy and roles of APNs. ${ }^{[27]}$

\subsection{The educational paradigm}

Contemporary pedagogical approaches to PMHNP curriculum are to transition nurses from earlier sub-specialty models (e.g., clinical nurse specialist or pediatric nurse practitioner). ${ }^{[4,18]}$ This is achieved by merging some essential practice elements with new evidenced-based knowledge, skills and competencies to create a more consolidative, knowledgeable, pragmatic, patient/family-centered group of PMHNPs. ${ }^{[4,17,18]}$ These practitioners would be competent in conducting comprehensively integrated psycho-neurobiological, psychological and psychosocial assessments, formulate supporting diagnoses, and providing best-practice pharmacological and non-pharmacological interventions across the lifespan. ${ }^{[4,18]}$ They would also be skilled interdisciplinary and interprofessional collaborators.

As previously alluded to, the highly specialized and yet inherently complex nature of the psychiatric clinical environment could prove educationally and interpersonally challenging to some PMHNP students' perceptual, attitudinal, and theoretical understanding. An example, the ubiquitousness of a patient's ego-syntonic personality-typed defense mechanism can exhibit idiosyncratic behaviors that can easily impede students' ability to form the therapeutic alliance necessary to provide authentic patient-centered care. These maladaptive interpersonal patients' qualities could add to the naive/novice PMHNP student's already stressful educational learning process. Therefore, PMHNP students' educational theory and practice accomplishments are through the careful merging and balancing of their emotional and cognitive processes, as well as understanding the wide-ranged scientific principles guided by the preceptor's knowledge and support aimed at achieving clinical and practice mastery. ${ }^{[17]}$ The preceptor supports the educational paradigm by creating a positive teaching and learning experiences through strong connect- 
edness along with being authentic, intentionally reflective and compassionate during students' engagements. These processes facilitate students' development of self-knowledge, critical and reflective thinking, and positive engagement that is consistently being modeled and evaluated by the preceptor. ${ }^{[13,25]}$

\subsection{The clinical paradigm}

The PMHNP-student clinical paradigm is built around and supported by independently achieving targeted goals and objectives including but not limited to assessment, diagnoses, and prescribing. It is also guided by legal and ethical practice principles, patients' spiritual and cultural aspects, as well as health promotion and disease prevention with emphasis on the monitoring of targeted treatment, response, remission, relapse prevention, and recovery. ${ }^{[28]}$ An important clinical goal for the PMHNP student is to use experiential case examples to stimulate thoughtful reasoning process to arrive at critical decision making praxes. As an example: after thoroughly evaluating a patient; deciding if the symptoms/presentation meet the Diagnostic and Statistical Manual of Mental Disorders, Fifth Edition (DSM-5) criteria for a psychiatric diagnosis; or whether the patient is experiencing circumstances that fall into categories of non-psychiatric conditions listed as in the "V Code" section of the DSM-5. Seminal work by Shawler (2008) ${ }^{[29]}$ supports the theory that PMHNP preceptorship exposes students to a patient-centered framework that helps them build on theoretical constructs such as the psychopathological and psychobiological theories contributing to disorders. Shawler $(2008)^{[29]}$ also reasoned the importance PMHNP students' ability to develop and use diagnostic reasoning skills to conceptualize case, formulate diagnoses, and prescribe appropriate treatment; while learning the terminologies needed to document in clinically relevant and measurable terms. Phases of the PMHNP-student clinical preceptorship should also reflect the pace and acuity of such diverse and real-world environments. The psychiatric emergency department (PED) is one example. This is a highly acute and active clinical environment that presents its own inherent challenges (e.g., exposure to violence) and opportunities (e.g., exposure to valuable crisis intervention skills and techniques). In this environment, the ability to conduct accurate, clear, and concise assessments, formulate practical working diagnosis(s) with well-thought-out decisions in a short period of time is of high importance. The preceptor therefore helps the student to understand and apply principles of critical thinking, reasoning, and organizing that translates into prioritizing the type of care that allows for more rapid stabilization and speedy transition of patients to another level of care. These hit-the-ground running, think-on your-feet exposures offer beneficial real-world experiences that are

Published by Sciedu Press vital to clinical socialization and skillset development. In those hectic clinical environments, it is essential for students to learn how to streamline clinical information to only what is necessary to make immediate treatment decisions, while differential history is obtained at other times and locations time by interdisciplinary/interprofessional team members.

In many cases, PEDs give rise to acute care inpatient units where patients are being treated for symptoms related to wide ranges of co-occurring and co-morbid conditions. These include but not limited to psychosis, mania, substance intoxication/withdrawals, or suicide. These environments offer students the opportunity to appreciate how interdisciplinary collaborative and integrative professional roles influence comprehensive care and expansion of services for SMI individuals. ${ }^{[26]}$ Outpatient psychiatric centers (e.g., hospital or community-based clinic) are examples of transitional and/or referral sources where patients and families can inquire about and access services. These clinical environments offer PMHNP students important immersion experiences with regard to interactively and holistically caring for persons living with serious mental illness (SMI). The role and function of these service centers reinforces the concept that SMI individuals can live within their communities, maintain stability and achieve recovery through comprehensivelystructured, collaborative and integrative care models. ${ }^{[26]}$

Important clinical pearls for the PMHNP student precepting in these environments include some evidence-based indicators grounded in the principles of patients achieving: (1) favorable response to treatments, (2) remission of illnesses, relapse preventions, rehabilitation and recovery. ${ }^{[26]}$ This is in addition to experiencing the therapeutic value of the authentic nurse-patient-family motivational engagement relationships provided through principles of interdisciplinary, collaborative, integrated, and expanded care and services outcomes. ${ }^{[4,28]}$ Other clinical areas such as forensic psychiatry, allows the PMHNP student to gain important insights into how the expanded roles of APNs influence caring for SMI persons in nontraditional psychiatric settings. In these clinical environments, important educational praxis include how the blending roles of correctional, psychiatric, and medical professionals have merged to provide one single standard of best practice care for SMI patients who are incarcerated. ${ }^{[30]}$ It is from these immersed preceptor-students clinical experiences that students learn to reflect and synthesize theoretical perspectives with caring concepts and current evidence to develop insights into the PMHNP roles.

\subsection{The practice paradigm}

The nursing literature overwhelmingly supports preceptorship as a model for experiential teaching and learning within 
the context of practice paradigms. ${ }^{[1,5,6,8,10,16,31]}$ The literature also documents how students perceived developing and/or fine-tuning their hard and soft skills through independent functioning that is validated by the preceptor. ${ }^{[4,16]}$ The PMHNP student's clinical practicum involves much more than just accumulating the number of clinical hours required for program graduation and certification to practice. ${ }^{[1,17]}$ Of high importance are the hands-on practice experiences aimed at achieving those hard and soft clinical skills under the constructive supervision, mentoring, and evaluation of the enthusiastic preceptor. For instance, this author observed that some of these practice experiences include but not limited to (1) using current practice guidelines to guide clinical reasoning and decision making processes; (2) understanding and applying concepts and principles of legal and ethical decision making, including advocacy; and (3) practicing the art of clinically descriptive documentation justifying care provided, meeting regulatory guidelines, as well as for third party reimbursements. These practice algorisms allow students to gain clearer understanding of their future professional roles, identify their strengths and limitations, and identify how/when to seek clinical consultation or supervision during practice.

Elisabeth et al. (2009) ${ }^{[16]}$ suggested that once the trusted preceptor-student relationship has been established the preceptor can use a three-step hierarchical approach to delegate more independent practicing latitude and responsibilities. In the first step, the student has the clinical control with the preceptor visibly present to give gentle guidance. During the second step, the student maintains control with the preceptor in the periphery (the invisible presence). The preceptor takes mental/written notes to review with the student. This continuous engagement approach promotes students' active participation, encourages reflective questioning, which allows the preceptor to give clinical practice skills feedbacks. ${ }^{[1]}$ The last step allows the student to independently conduct the assessment and develops the intervention before presenting the case to the preceptor. The preceptor in turn conducts a face-to-face patient assessment; make any adjustments with teaching rational before signing off on the case. Overall, it is educationally beneficial for PMHNPs students to be exposed to varying clinical case presentations, scenarios, or

\section{REFERENCES}

[1] Davis LF, Fathman AE. Clinical education of nurse practitioner students: Identifying incentives, barriers, and working models to develop sustainable preceptorships. Journal of Nursing Education and Practice. 2018; 8(9): 18-24. https ://doi.org/10.5430/jnep.v $8 \mathrm{n} 9 \mathrm{p} 18$ circumstances within the context of their practice paradigm. This three-step process provides allows them the essential hands-on opportunity which helps to build practice skills confidence.

\section{Conclusion}

Despite the many barriers to precepting identified by Davis \& Fathman (2018), ${ }^{[1]}$ PMHNP preceptorship will continue to be integral to university schools of nursing's programs' success in producing competent practitioners who continue meet parity and best practice standards in the delivery of mental health care and services. ${ }^{[26]}$ This paper discusses the extent the literature supports establishing the types of relationships and environments aimed at achieving a successful PMHNP-student clinical preceptorship. This includes Lucas \& Bischof (2014) $)^{[7]}$ and Trede, Sutton \& Bernoth (2016) ${ }^{[9]}$ who noted that preceptors should provide the environment and teaching strategies conducive to learning and retaining of information. Putting the concept of PMHNPstudent preceptorship into reflective focus is in line with our contemporary society's evolving health conditions, healthcare sectors, delivery of health care; and where innovative and transformative educational approaches are necessary to keep pace. It also affirms and supports the continued dedication to invest in the future of nursing through educational advancements, empirical researches, evidence-based clinical practices, and effective leaderships at all levels and specialties. The conclusion drawn from this review is that a successful PMHNP-student preceptorship practicum is a necessary element for transitioning students into qualified and sustainable future practitioners. This practicum is aided by the qualified preceptor who provides knowledge and insight, mentors and inspires and makes positive differences in students' lives. It is the hope that this review will offer useful clinical and educational perspectives on the nature of the PMHNP student-preceptor-faculty relationship as well as influencing future university schools of nursing curriculum development aimed at quality education and practice outcomes.

\section{CONFLiCtS OF INTEREST Disclosure}

The author declares that there is no conflict of interest.
[2] Delamaire ML, Lafortune G. Nurses in advanced roles: A description and evaluation of experiences in 12 developed countries. OECD Health Working Papers. 2010.

[3] Sheikh KR. Expanding clinical models of nurse practitioner education: Service learning as a curricular strategy. The Journal for Nurse Practitioners. 2014; 10(5): 352-355. https://doi.org/10.1016/ 
j.nurpra. 2014.03.009

[4] Tusaie KR. Are advanced practice psychiatric mental health nurses prepared to deliver integrated care?. Archives of Psychiatric Nursing. 2013; 27(1): 1-2. PMid:23352019 https://doi.org/10.1016/j. apnu. 2012.10.003

[5] Payne C, Heye ML, Farrell K. Securing preceptors for advanced practice students. Journal of Nursing Education and Practice. 2013; 4(3): 167-179. https://doi.org/10.5430/jnep.v4n3p167

[6] Bazzell AF, Dains JE. Supporting Nurse Practitioner Preceptor Development. The Journal for Nurse Practitioners. 2017; 13(8): e375-e382.

[7] Lucas D, Bischof J. Advancing nurse practitioner preceptor and student engagement in evidence-based practice at the point of care. The Journal for Nurse Practitioners. 2014; 10(8): e25-e31.

[8] Luhanga FL, Billay D, Grundy Q, et al. The one-to-one relationship: Is it really key to an effective preceptorship experience? A review of the literature. International Journal of Nursing Education Scholarship. 2010; 7(1): 1-15.

[9] Trede F, Sutton K, Bernoth M. Conceptualisations and perceptions of the nurse preceptor's role: A scoping review. Nurse Education Today. 2016; 36: 268-274. PMid:26276530 https://doi.org/10.1016/ j.nedt.2015.07.032

[10] Marfell J. Preceptors-The cornerstone of clinical education. The Nurse Practitioner. 2011; 36(6): 6-7. PMid:21572291 https://do i. org/10.1097/01.NPR.0000397918.13316.f7

[11] Fitzpatrick S, Gripshover J. Expert nurse to novice nurse practitioner: the journey and how to improve the process. The Journal for Nurse Practitioners. 2016; 12(10): e419-e421.

[12] Haitana J, Bland M. Building relationships: The key to preceptoring nursing students. Nursing Praxis in New Zealand. 2011; 27(1): 4.

[13] Buck KD, Lysaker PH. Clinical supervision for the treatment of adults with severe mental illness: Pertinent issues when assisting graduate nursing students. Perspectives in Psychiatric Care. 2010; 46(3): 234-243. PMid:20591130 https://doi .org/10.1111/j. 1744-6163.2010.00258.x

[14] Alexander V, Ellis H, Barrett B. Medical-surgical nurses' perceptions of psychiatric patients: a review of the literature with clinical and practice applications. Archives of Psychiatric Nursing. 2016; 30(2): 262-270. PMid:26992881 https://doi.org/10.1016/j. apnu. 2015.06.018

[15] Fitzpatrick JJ. Helping nursing students develop and expand their emotional intelligence. Nursing Education Perspectives. 2016; 37(3): 124. https://doi.org/10.1097/01.NEP.0000000000000020

[16] Elisabeth C, Christine WH, Ewa P. Teaching during clinical practice: Strategies and techniques used by preceptors in nursing education. Nurse Education Today. 2009; 29(5): 522-526. PMid:19108935 https://doi.org/10.1016/j.nedt.2008.11.012

[17] Schumacher G, Risco K. Competency-Based Nurse Practitioner Education: An Overview for the Preceptor. The Journal for Nurse Practitioners. 2017; 13(9): 596-602. https://doi.org/10.1016/ j.nurpra. 2017.07.020

[18] Weber MT, Delaney KR, Snow D. Integrating the 2013 psychiatric mental health NP competencies into educational programs: Where are we now?. Archives of Psychiatric Nursing. 2016; 30(3): 425-431. PMid:27256952 https://doi.org/10.1016/j . apnu. 2015.12 .004
[19] Ares TL. Professional socialization of students in clinical nurse specialist programs. Journal of Nursing Education. 2014; 53(11): 631640. PMid:25350045 https://doi.org/10.3928/01484834-2 0141027-03

[20] Ehrenberg AC, Häggblom M. Problem-based learning in clinical nursing education: Integrating theory and practice. Nurse Education in Practice. 2007; 7(2): 67-74. PMid:17689426 https: //doi.org/10.1016/j.nepr.2006.04.005

[21] Benham B, Hawley D. The effectiveness of tools used to evaluate successful critical decision making skills for applicants to healthcare graduate educational programs: A systematic review protocol. JBI Database of Systematic Reviews and Implementation Reports. 2015; 13(4): 231-275.

[22] Kirkbakk-Fjær K, Andfossen NB, Hedelin B. Preceptors' expectations of nursing students' preparation before placement in psychiatry: Ability and will to reflect on and exercise knowledge. Issues in Mental Health Nursing. 2012; 36(4): 300-306. PMid:25989194 https://doi.org/10.3109/01612840.2014.978424

[23] Munnukka T, Pukuri T, Linnainmaa $P$, et al. Integration of theory and practice in learning mental health nursing. Journal of Psychiatric and Mental Health Nursing. 2002; 9(1): 5-14. https: //doi.org/10.1046/j.1365-2850.2002.00393.x

[24] Miller B, Carr KC. Integrating standardized patients and objective structured clinical examinations into a nurse practitioner curriculum The Journal for Nurse Practitioners. 2016; 12(5), e201-e210.

[25] Schwindt R, McNelis A. Integrating simulation into a reflectioncentered graduate psychiatric/mental health nursing curriculum. Nursing Education Perspectives. 2015; 36(5): 326-328. https: //doi.org/10.5480/15-1614

[26] Ellis H, Alexander V. Eradicating barriers to mental health care through integrated service models: contemporary perspectives for psychiatric-mental health nurses. Archives of Psychiatric Nursing. 2016; 30(3): 432-438. PMid:27256953 https://doi.org/10.1 016/j . apnu. 2016.01.004

[27] Fitzgerald C, Kantrowitz-Gordon I, Katz J, et al. Advanced practice nursing education: challenges and strategies. Nursing Research and Practice. 2012.

[28] Ellis HA. The Crisis Intervention Team-A Revolutionary Tool for Law Enforcement: The Psychiatric-Mental Health Nursing Perspective. Journal of Psychosocial Nursing and Mental Health Services. 2011; 49(11): 37-43. PMid:22007851 https://doi.org/10.392 8/02793695-20111004-01

[29] Shawler C. Standardized patients: A creative teaching strategy for psychiatric-mental health nurse practitioner students. Journal of Nursing Education. 2008; 47(11): 528-531. https ://doi .org/10.392 8/01484834-20081101-08

[30] Ellis H, Alexander V. The Mentally Ill in Jail: Contemporary Clinical and Practice Perspectives for Psychiatric-Mental Health Nursing. Archives of Psychiatric Nursing. 2017; 31(2): 217-222. PMid:28359436 https://doi.org/10.1016/j . apnu. 2016.09 .013

[31] Hawkins-Walsh E, Crowley A, Mazurek Melnyk B, et al. Improving health-care quality through an AFPNP National Nursing Education Collaborative to strengthen PNP curriculum in mental/behavioral health and EBP: Lessons learned from academic faculty and clinical preceptors. Journal of Professional Nursing. 2011; 27(1): 10-18. 